\title{
THE RISK OF VAMPIRE EFFECT IN ADVERTISEMENTS USING CELEBRITY ENDORSEMENT
}

\author{
Kuvita, T., Karlíček, M.
}

In the race to get the attention of the target audience, advertisers often use special attention-getting devices. This in turn exposes them to a higher risk of creating a vampire effect when the core message about the brand or a product is "eaten up" by such devices. The concept of a vampire effect in advertising appears to be under-researched in the current literature. Therefore, this paper provides deeper insights into the vampire effect occurrences in printed advertisements using celebrity endorsement. The paper is based on a qualitative study with an eye-tracking device with 12 participants and on the following experiment with 60 university students. The research found that a significantly higher risk of creating a vampire effect exists when using an unrelated celebrity as an attention-getting device than when using a related celebrity or no celebrity at all. Marketers are advised to use related celebrities if choosing to stick to this attention-getting approach. However, the concept of "relatedness" should be pre-tested prior to launching an advertising campaign.

JEL classification: M370

Keywords: vampire effect; celebrity endorsement; attention-getting device

\section{Introduction}

Nowadays marketers face extensive challenges when communicating with potential customers. The race for getting the attention of a target audience is vast due to the information overload of modern society. In an attempt to stand out from other advertising messages, marketers take the risk of getting trapped into the so-called vampire effect of their own advertising campaigns: tools for getting attention "suck" customer attention away from core messages of the advertisement.

Despite the fact that a lot of studies have been done concerning the effectiveness of advertising, little attention has been drawn to this phenomenon. Thus, this study aims to explore the risks of vampire effect in advertising using celebrity endorsement and to provide recommendations for preventing its occurrences.

\section{Literature Review}

Nowadays with the increasing amount of information available worldwide, it gets rather hard for an advertiser to create an effective marketing communication campaign. "The chase for reaching an audience is becoming more complex, and getting people to sit down to hear a message is challenging" (Gobe, 2009, p. 243). Furthermore, even when the message is delivered, it is hard to ensure that the receiver understood it in the correct manner. Besides, the targeted group could get overloaded with marketing messages. Information overload is generally defined as "the state of an individual in which not all communication inputs can be processes and utilized, leading to breakdown" (Quentin, 2004, p.196). Cognitive psychologists proved that because a person has a limited capacity to process information, he/she creates a filter to prevent the information-processing system from overloading (McLeod, 2008). Applying this theory to marketing simply suggests that with being exposed to too many advertising messages, a consumer creates his/her own filter in order to deal with overload. In the struggle for attention and getting their message through to the target audience, marketers often use so-called attention-getting devices (AGDs). AGD may be defined as any element in a marketing communication campaign designed to gain the attention of the audience but which does not contain the core message of the campaign. Humor, erotic stimuli and celebrities are among the most commonly used AGDs. 
According to information overload theory, in times when a person receives too much information, the captivation of a piece of information occurs at the expense of another piece of information (Salyer, 2013). This in turns means that using AGDs should help in attention stimulation; however, they could also distract customers from receiving the necessary information about the product and brand and, thus, create a vampire effect.

The vampire effect can generally be defined as an image, object or person, which grabs the attention of the target audience away from the product or the brand (or other product/brand related messages) and, thus, prevents customers from remembering the product or the brand. A difficulty in identifying these "vampires" in advertising lies in the fact that any image used in an advertisement has a risk of taking away the attention.

No general definition of the term vampire effect is provided in academic literature; nevertheless, such phenomena as vampire claims and vampire videos are discussed which in turn help to understand the idea behind it.

High risk of vampire effect is associated with using celebrities in advertising. The probability of vampire effect occurrence increases when there is no congruency between the celebrity and a brand or a product. When the celebrity endorsing the product does not have any relation to the product he or she endorses, the vampire effect is more likely to occur (Erdogan, 1999). Similarly, a study of Speck, Schumann and Thompson found out that related celebrities produced higher product recall than unrelated celebrities (Erdogan, 1999). Nonetheless, the difference was not statistically significant, and thus the outcome should be further verified.

Vampire effect in the context of celebrity endorsement occurs when the celebrity overshadows the product featured in the advertisement. A Cyber Media Research study reveals a high percentage of vampire effect occurrences: 80 percent of respondents in this study could remember a celebrity but not the brand (Okorie, Oyedepo and Akhidenor, 2012). It is also believed that the probability of vampire effect occurrence increases if an internationally unknown brand uses an international celebrity (Erdogan and Baker, 1999). In such cases, it is more likely that potential consumers will pay attention to the celebrity and not to the brand.

An example of overshadowing and absence of clear consistency with the product and celebrity advertising the product may be Celine Dion's endorsement by Chrysler (Stein, 2003). After signing a three-year contract with the singer for $\$ 14$ million, the company soon realized that effectiveness of celebrity endorsement turned out to be a disaster. Ms. Dion was featured in advertisements for the 2004 Chrysler Pacifica sport wagon, the Crossfire coupe and the Town \& Country minivan. At that time, the company's strategy was to move the brand towards younger and more affluent customers. However, focus groups revealed that the average age of audience to whom Ms. Dion appealed was 52. The problem went so much further that in the end the company had to reposition its product and make the Pacifica car targeting consumers averaging 53 years old.

Therefore, vampire effect in advertising is an important issue, since the occurrences of it may be quite hard to predict. Thus, it needs to be studied in a greater detail.

Goal and Methodology

Based on a literature review, this study focused on researching whether advertisements that use a celebrity as an AGD were more likely to create a vampire effect than those that do not use any AGD. However, the differentiation between related and unrelated celebrities as described by Speck, Schumann and Thompson was used. Thus, the following hypothesis was formulated:

H1: Print advertisements that use unrelated celebrities as AGD are more likely to create a vampire effect than those that use related celebrities as AGD or those that use no AGD at all:

a) Print advertisements that use unrelated celebrities as AGD are more likely to create a vampire effect in terms of taking attention away from the product.

b) Print advertisements that use unrelated celebrities as AGD are more likely to create a vampire effect in terms of taking attention away from the brand.

c) Print advertisements that use unrelated celebrities as AGD are more likely to create a vampire effect in terms of taking attention away from other product relevant statements.

In order to test the hypothesis, three advertisements were created (see Figure 1): one advertisement featuring a celebrity unrelated to the product advertised (Angelina Jolie used for promotion of a retro guitar store), one advertisement featuring a celebrity related to the product (Elvis Presley used for promotion of a retro guitar store) and one advertisement not featuring any celebrity as an AGD.

The study was performed in two phases. In the first stage, testing of printed ads was done with the help of an eye-tracking device and included 12 participants (university students). Participants had to take a look at a series of five advertisements, among which one of the ads from Figure 1 was mixed. 


\section{Figure 1 Tested advertisements}
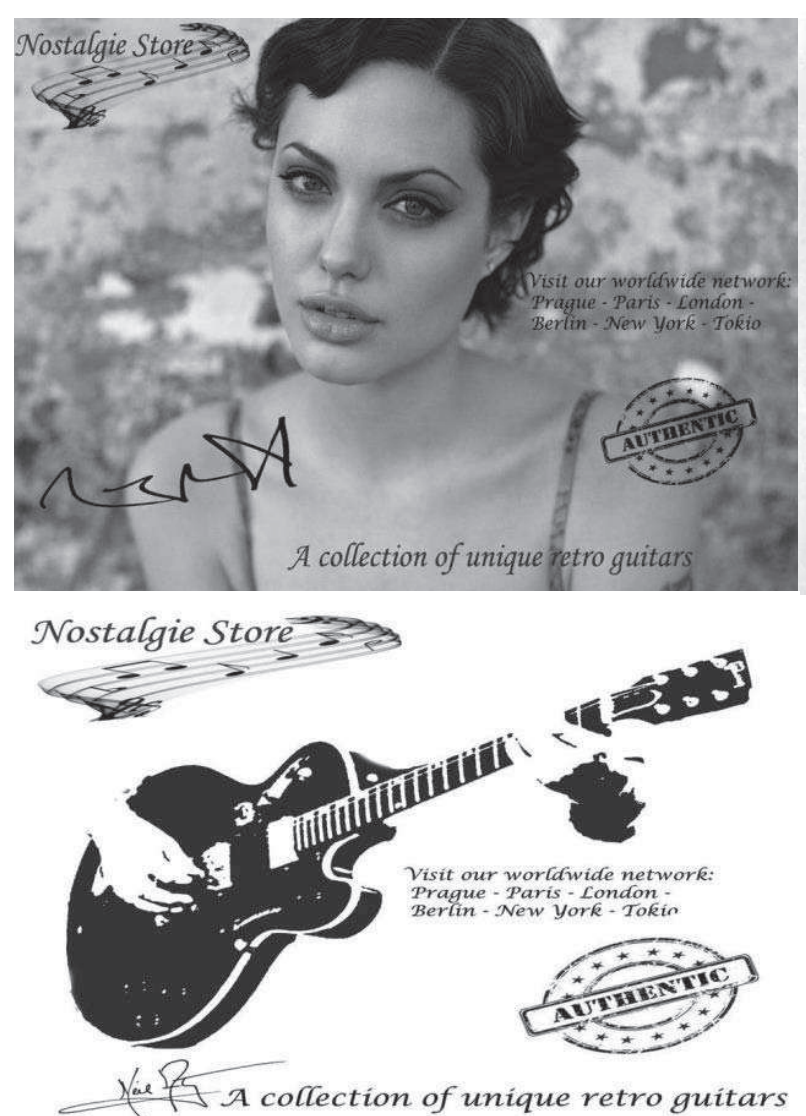

Specifically, four participants were exposed to an ad with a non-related AGD, four participants to an ad with a related AGD, and four participants to an ad without any AGD. Each ad was shown to the participants for a period of five seconds. Afterwards, participants were asked to fill in a survey. After collecting information, the following outputs from the eye-tracking device were generated: heat maps, scan paths, as well as clustering of gaze. Based on this, the researchers could see typical ways each advertisement was looked at as well as attention distribution on each of them. Additionally, the results of this stage helped to adjust the questions for the survey used more broadly in the next stage.

The second phase was an experiment with 60 students (university students as well). During this stage, participants were divided into three groups of 20 people and exposed to the same mixture of advertisements in the same manner as in the first stage. Thus, the first group saw the advertisement with an unrelated celebrity as

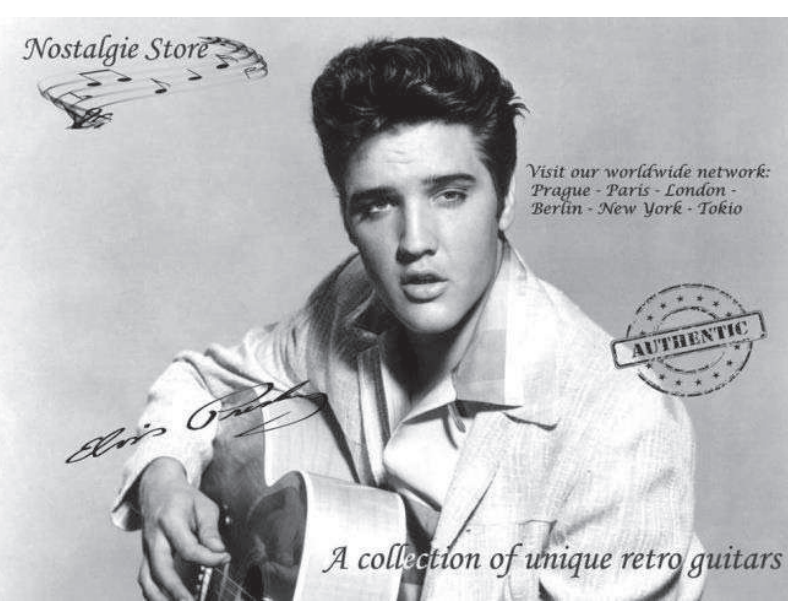

Figure 1a-c (clockwise from top left):

1a: unrelated celebrity advertisement;

$1 \mathrm{~b}$ : related celebrity advertisement;

1c: advertisement without a celebrity.
AGD, the second - advertisement with related celebrity as AGD and, finally, the third group - advertisement with no celebrity as AGD. It is necessary to notice that the survey stage also had some qualitative inputs: respondents had to answer open-ended questions. Thus, the research approach was a combination of exploratory and conclusive research. Afterwards, students were asked to fill in a survey. Subsequently, the results were inserted into SPSS for conducting statistical analysis. The researchers used the Kruskal-Wallis test for identifying whether there were significant differences between the three sample groups in recall levels of different parts of the tested advertisements.

\section{Findings}

As discussed previously, a general definition of the vampire effect suggests that an AGD "eats" the attention of the target group away from the core messages of the advertisement - brand, product and other messages related to the product. 
The researchers analyzed the survey results using a non-parametric test of comparing means. This was done due to the fact that data was not normally distributed and since the number of independent groups to compare was more than two, the Kruskal-Wallis test was chosen for analysis. The necessary assumptions of homogeneity of variances and similar distributions were met for each analysis performed.

Survey analysis showed that in terms of levels of remembering of the ad image, ads with celebrity endorsement showed better results than the ad picturing a guitar (see Figure 2). Further statistical testing using the Kruskal-Wallis test showed that the difference between the groups was significant (Chi-square $=7,549$; $p=0,023<0,05)$. Specific comparison testing revealed that a statistically significant difference in remembering AGD was between group 1 and group 3 (Chi-square = $4,789 ; p=0,029<0,05)$; and between groups 2 and 3 (Chi-square $=6,240 ; p=0,012<0,05)$. The control group had a significantly lower image recall level (Mean ranks: $\mathrm{G} 1=33,5 ; \mathrm{G} 2=35,0 ; \mathrm{G} 3=23,0$ ). These results were also consistent with the results of the eye-tracking experiment: participants exposed to advertisements with celebrity endorsement drew more attention to the faces of celebrities, whereas participants from the control group drew less attention to the picture of a guitar.

\section{Figure 2 Comparison of the ad image and product recall} levels

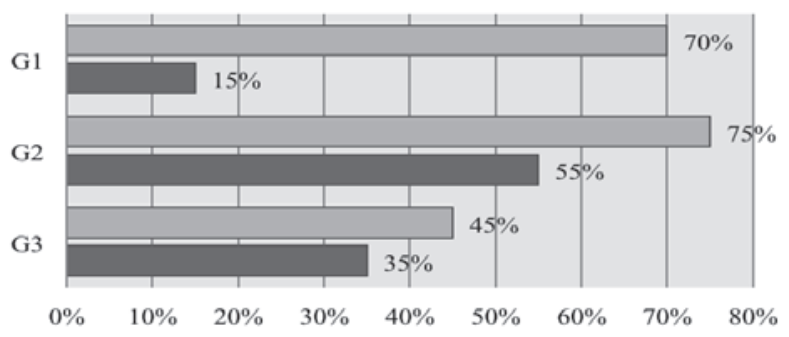

$\square$ Image Recall $\square$ Product Recall

Source: authors

However, the levels of product recall had reverse results (see Figure 2). There was a significant difference between the three groups in terms of product recall (Chi-square $=$ $12,701 ; p=0,002<0,05)$. Specifically, there was a difference between groups 1 and 2 (Chi-square $=$ $12.584 ; p=0.00<0.05$ ) and groups 1 and 3 (Chi-square $=$ 5.991; $p=0.014<0.05)$. Thus, ads with unrelated celebrity endorsement (G1) showed significantly lower levels of product recall (Mean ranks: G1 $=21,5$; G2=
$38,0 ; \mathrm{G} 3=32,0)$. In other words, even though participants could much better remember a celebrity (Angelina Jolie) in the ad they saw, they did not remember which product she endorsed. The null hypothesis of this part (a) was therefore rejected. It was thus concluded that an unrelated celebrity ad showed the highest risk of vampire effect. In relation to part b) of the hypothesis - drawing attention away from the brand - no statistical proof was found. Participants generally showed a very low level of brand recall across three groups as can be seen in Figure 3. Groups two and three had the same recall levels of 20 percent; however, unrelated celebrity ad (group 1) yielded no recall of brand information at all. However, the Kruskal-Wallis test revealed that there was no statistically significant difference between the three groups $($ Chi-square $=4.538 ; p=0.103>0.05)$.

\section{Figure 3: Comparison of ad image and brand recall levels}

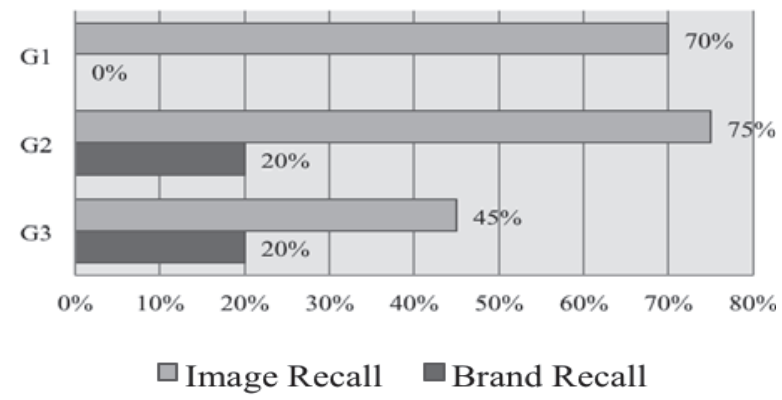

The null hypothesis of this part was hence not rejected. There was no significant difference between the three groups in terms of brand recall. These results are also consistent with the output from the eye-tracking experiment: the eye-tracking device spotted almost no direct look at the brand logo. Participants looked at the logo mostly indirectly, without actively seeing the name of the company. This lack of attention towards the brand could be due to the wrong placing of the logo in the advertisement or the limited amount of time given to participants. Further discussion of reasons for not having a direct attention drawn to the logo of the company, however, goes beyond the scope of this study.

Speaking about part c) of the hypothesis, the related AGD ad had a significantly higher level of other product related statements recall than the other two advertisements. Survey results showed the best recall levels in the group exposed to related AGD ad (70\%) as can be seen in Figure 4. The lowest recall levels were observed in the groups with respondents seeing an unrelated celebrity as AGD advertisement - only 5 percent could remember other statements. Performing the Kruskal-Wallis test 
Table 1 Measures of association levels between celebrity and product recall for test group 2

\begin{tabular}{|l|r|c|c|c|c|}
\hline \multicolumn{7}{|c|}{ Chi-Square Tests and Symmetric Measures } \\
\hline & Value & df & $\begin{array}{c}\text { Asymp. Sig. } \\
\text { (2-sided) }\end{array}$ & $\begin{array}{c}\text { Exact Sig. } \\
\text { (2-sided) }\end{array}$ & $\begin{array}{c}\text { Approx. } \\
\text { Sig. }\end{array}$ \\
\hline Pearson Chi-Square & $5.089^{a}$ & 1 & .024 & & \\
\hline Fisher's Exact Test & & & & .050 & \\
\hline & & & & & \\
\hline Cramer's V & 0.504 & & & & 0.024 \\
\hline N of Valid Cases & 20 & & & & \\
\hline
\end{tabular}

Source: authors

showed that the difference was statistically significant (Chi-square $=14,359 ; p=0,001<0,05)$. Specifically, the difference laid between groups 1 and 2 (Chi-square $=$ $12,769 ; p=0,000<0,05)$ and groups 2 and 3 (Chi-square $=$ $6,240 ; p=0,012<0,05)$. Related AGD advertisement had the highest recall levels (Mean ranks: $G 1=23,0$; $\mathrm{G} 2=40,15 ; \mathrm{G} 3=28,35)$.

\section{Figure 4: Comparison of ad image and other statements} recall levels

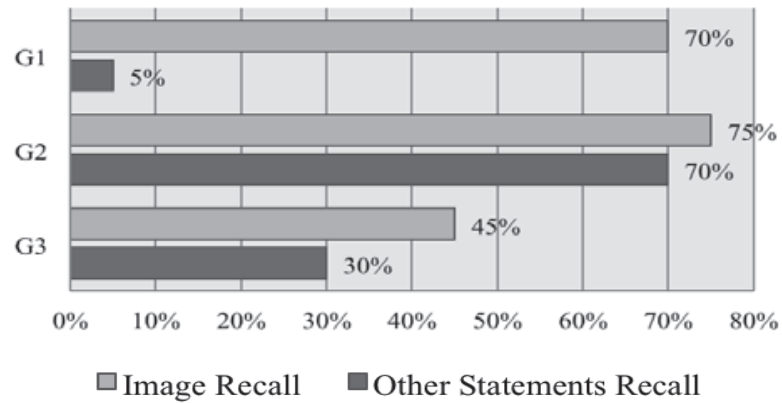

Source: Authors

The null hypothesis can thus be rejected. The unrelated AGD ad had still lower levels of other product related statements recall, which, together with AGD recall levels, suggests that this ad showed the highest risk of a vampire effect as compared to the related AGD ad or to the ad without any AGD. Compared to the results of the eye-tracking experiment, this conclusion is consistent as well: the gaze scans of the unrelated AGD ad showed almost no coverage of product/brand related statements, whereas gaze scans of the related AGD and non AGD ad partially covered these statements.

Noteworthy, however, was also the fact that even though the gaze scan coverage of the control ad was much broader and covered other product/brand related statements much better, the recall levels of the participants were significantly lower as compared to the recall levels of participants who saw a related celebrity as AGD ad. Yet, there was no statistically significant difference in other statement recalls between the control ad and the unrelated celebrity as AGD ad. More detailed analysis is, therefore, necessary to explain this phenomenon.

Therefore, since two out of three subparts of the hypothesis were not rejected, the research concluded that overall, the null hypothesis of the study was rejected. Therefore, the study found that there is a significantly higher risk of creating a vampire effect when using an unrelated celebrity in print advertising than when using a related celebrity or no celebrity at all. Furthermore, related celebrity endorsement could be an effective tool in printed advertising. However, the level of relatedness of an attention-getting device can rarely be measured precisely since perceiving a celebrity related to a product/ brand advertised is subjective.

Furthermore, using no AGD has a risk of being ignored by the target market. As revealed by testing, the perception levels of advertisements being able to effectively grab attention of the audience, the advertisement with no celebrity as AGD (G3) had the worst results: only 5 percent of respondents believed the ad effectively grabbed their attention $(\mathrm{G} 1=45 \%$; G2 $=35 \%)$. Statistically, the difference was significant (Chi-square $=$ $9,486 ; \mathrm{p}=0,009)$. The difference laid between groups 2 and 3 (Chi-square $=8.142 ; \mathrm{p}=0.004<0.05)$ and groups 1 and 3 (Chi-square $=6.080 ; \mathrm{p}=0.014)$. The mean ranks of the Kruskal-Wallis test were the following: $\mathrm{G} 1=35,1$; $\mathrm{G} 2=35,6 ; \mathrm{G} 3=20,8$. Indeed, the control group was much less likely to perceive the advertisement they saw to be catchy, whereas the groups exposed to advertisement with celebrities as AGD had the opposite result. 
Additionally, the hypothesis that the risk of vampire effect is higher for unrelated celebrity advertisement is also supported by the perception of advertisement consistency. The analysis of the survey results revealed that the advertisement that used unrelated celebrity as AGD had the worst perception of consistency -20 percent of respondents thought the ad was consistent as compared to 55 percent in group 2 and 25 percent in group 3 . Participants in the group had the weakest belief that all messages in the advertisement made sense all together. Statistical analysis of significance confirmed there was a difference (Chi-square $=5,972, p=0,05=0,05$ ) between the three groups. Mean rank distributions were the following: $\mathrm{G} 1=25,53 ; \mathrm{G} 2=38,08 ; \mathrm{G} 3=27,9$. Yet, the difference was only between groups 1 and 2 (Chi-square $=$ 5.773; $p=0.017<0.05$ ). There was, however, no statistically significant difference between groups 1 and 3 (Chi-square $=0.109 ; p=0.741>0.05)$, as well as between groups 2 and 3 (Chi-square $=3.070 ; \mathrm{p}=0.080$ $>0.05)$. Even though no deeper analysis of such perception was done, it could be assumed that unrelated celebrity created an imbalance in communication effort of the company and, thus, could eventually lead to a vampire effect. Coming back to previous studies, Erdogan (1999) had already theorized that when a celebrity endorser did not have an associated relation to the product, a vampire effect tended to occur. The fact that the control advertisement was also perceived as quite inconsistent, since only 25 percent of participants believed it was, could be due to the low levels of the ad recall.

Furthermore, as was discussed previously, Speck, Schumann and Thompson (Erdogan, 1999) found out that related celebrities produced higher product recall than unrelated, but did not have statistical proof for that. This study shed more light on the discussion. The statistical analysis of survey results showed positive statistical association between the levels of the celebrity recall and the level of product recall in the group exposed to the advertisement with related celebrity (Table 1). Thus, the theoretical belief that in cases of using celebrity endorsements, if done correctly by achieving the degree of consistency between the product and the celebrity endorsing it, movement of meaning may occur. In other words, if consumers see a logical link between an endorser and a product, they are more likely to remember the product.

\section{Conclusion and Managerial Implications}

Marketers should be able to find a balance between gaining the attention of their target audience and delivering product and brand related message. Gaining attention is the first step only; it is a means to an end rather than an end itself. As warned by previous researchers, this study showed once again that the race for creativity and attention getting could easily become a false priority. If the level of association between the AGD and the product or brand is not sufficient enough in the minds of the target audience, no value will be generated from such advertisement. The fact that the audience remembers the advertisement does not automatically mean they received the core message about the product or a brand. Using unrelated celebrities as AGD has a higher risk of creating a vampire effect. Nevertheless, even though an advertisement without any special AGD could be a safer option, it has a higher risk of being simply ignored by target groups. Therefore, in order to pass through the filter of consumers and get their attention, marketers might still need to use special AGDs. Consequently, when choosing to use celebrities as AGD, marketers should use related celebrities since, as discussed earlier by Speck, Schumann and Thompson (Erdogan, 1999) and proven by this study as well, they produce higher product recall. Nevertheless, this relation should be pre-tested prior to launching an advertising campaign. However, it should be noted that levels of relatedness between the celebrity and the target audience is hard to test, since this is a subjective and individual matter. Thus, in this regard, the study faces its limitations.

\section{References}

Erdogan, B.Z. (1999). Celebrity Endorsement: A Literature Review. Journal of Marketing Management. 15 (1): 291-314.

Erdogan, B. Z., Baker, M. J. (1999). Celebrity Endorsement: Advertising Agency Managers' Perspective. The CyberJournal of Sport Marketing, 3 (3).

Gobe, M. (2009). Emotional Advertising: Expressing Real Emotions Online, in Emotional Branding: The new paradigm for connecting brands to people. New York: Allworth Press, 223-244.

Heath, R. (2012). Problems with Getting Attention, in Seducing the Subconscious: The Psychology of Emotional Influence in Advertising. Hoboken: Wiley, 86-98.

McLeod, S. (2008). Selective Attention. Simply Psychology. (accessed January 20,2014), [available at http://www. simplypsychology.org/attention-models.html]

Okorie, N., Oyedepo, T., Akhidenor, G. (2012). The Dysfunctional and Functional Effect of Celebrity Endorsement on Brand Patronage. Online Journal of Communication and Media Technologies, 2 (2): 148-149. 
Quentin, J. (2004). Information Overload and the Message Dynamics of Online Interaction Spaces: A Theoretical Model and Empirical Exploration. Information Systems Research, 15 (2): 194-210.

Salyer, G. (2013). Information Overload: The effects of advertising avoidance on brand awareness in an online environment. (accessed January 20, 2014), [available at http://web02.gonzaga.edu/comltheses/proquestftp/Salyer gonzaga_0736M_10263.pdf]

Stein, J. (2003). Inside Chrysler and Celine Dion Advertising Disaster. Advertising Age. November 24.

Assoc. Prof. Miroslav Karlíček, Ph.D Marketing Department University of Economics, Prague Nám. W. Churchilla 4

This study was realized in cooperation with INCOMA GfK research agency and it was supported from the resources for long-term conceptual research development of the University of Economics, Prague (IP300040). 